\title{
Defusing practices as mitigation in speech and language intervention.
}

\author{
Christina Samuelsson, Charlotta Plejert and Jan Anward \\ Journal Article
}

\section{Tweet}

N.B.: When citing this work, cite the original article.

Original Publication:

Christina Samuelsson, Charlotta Plejert and Jan Anward, Defusing practices as mitigation in speech and language intervention., Communication \& Medicine, 2014. 11(3), pp.299-312. http://dx.doi.org/10.1558/cam.v11i3.24802

Copyright: De Gruyter / Equinox Publishing http://www.degruyter.com/

Postprint available at: Linköping University Electronic Press

http://urn.kb.se/resolve?urn=urn:nbn:se:liu:diva-130713

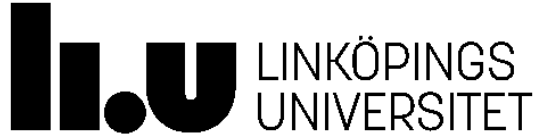


Author: Christina Samuelsson

Affiliation: Linköping University

Full address: Department of Clinical and Experimental medicine

SE-581 85 Linköping

Sweden

E-mail: Christina.samuelsson@liu.se

Author: Charlotta Plejert

Affiliation: Linköping University

E-mail: charlotta.plejert@liu.se

Author: Jan Anward

Affiliation: Linköping University

E-mail: jan.anward@liu.se

\section{Full title of article:}

Defusing practices as mitigation in speech and language intervention

\section{Short title of article:}

Defusing practices in intervention

Word Count (without abstract, transcription conventions, and references): 6457

Word count (all inclusive): 8271

Character Count (with spaces): 53175 


\section{Bionotes}

Christina Samuelsson received her PhD in Speech and Language Pathology from Lund University, Sweden. Her current position is associate professor of Speech and Language Pathology at Linköping University. Her research mainly concerns how people with communicative disabilities interact and use language, with a specific focus on prosody. Address for correspondence: Department of Clinical and Experimental Medicine, Linköping University, 58185 Linköping, Sweden. E-mail: christina.samuelsson@liu.se

Charlotta Plejert received her $\mathrm{PhD}$ in Linguistics from Linköping University. She is currently associate professor at the Department of Culture and Communication, Linköping University. Her research interests include Conversation Analysis, communicative disabilities in children and adults, and second language interaction and acquisition. Address for correspondence: Department of Culture and Communication, Linköping University, 58185 Linköping, Sweden. E-mail: charlotta.plejert@liu.se

Jan Anward received his $\mathrm{PhD}$ in Linguistics from Uppsala University. He is currently professor at the Department of Culture and Communication, Linköping University. His principal research interests are language as a dynamic system, life-long language learning, the use and development of linguistic resources in various interactional contexts, including informal conversation, classroom interaction, and speech therapy, and the place of individual voices in various interactional and cultural contexts. Address for correspondence: Department of Culture and Communication, Linköping University, 58185 Linköping, Sweden. E-mail: jan.anward@liu.se 


\begin{abstract}
In the present paper, speech and language intervention was investigated in order to explore the use and function of defusing practices. Defusing practices may be viewed as a special form of mitigation. In previous research, including studies on clinical interaction, mitigation has been described mainly as devices used in order to reduce unwelcome effects of an utterance, or reduce the discomfort of bad news. Defusing practices, however, appear to serve somewhat different functions, which are explored here. Data comprises video and audio recordings of eight intervention sessions with children with language impairment (LI), and six intervention sessions with adults with aphasia, The analysis revealed the following kinds of defusing practices: circumscriptions/figurative language, diminutive words, words like 'try' or 'test', placing the problem outside of the patient, collective pronouns, diminishing the speech and language pathologist's (SLP's) own competence, encouragement, and references to well-known phenomena. If SLPs are made aware of the practice and function of defusing, they may make conscious use of these practices in order to reduce face-threatening situations in intervention.
\end{abstract}

Keywords: Clinical interaction, Speech and language intervention, Mitigation, Defusing practices, Children with language impairment, Adults with aphasia 


\section{Introduction}

Speech and language intervention constitutes a special case of clinical interaction, since language and interaction are both the goal and the medium through which intervention is carried out. Speech and language intervention also includes a certain amount of potential face-threat, since it often focuses on crucial aspects of speech and/or language that cause problems for the patient. The patient's communicative inabilities are thereby highlighted. Speech and language pathologists (SLPs) frequently use practices of a mitigating nature in speech and language intervention. Mitigation is used in order to minimize the display of a potential face-threat, such as criticism or bringing bad news (Blum-Kulka 1990; Brumark 2006). Originally, the term mitigation in linguistics comes from speech act theory, and it was first defined by Fraser (1980) as 'a modification of a speech act: the reduction of certain unwelcome effects which a speech act has on the hearer' (Fraser 1980: 341), e.g. actions that soften criticism, or display understanding and sharing of discomfort in interaction.

In the present paper, speech and language intervention for children with language impairment (LI) and adults with aphasia is investigated. However, in contrast to previous settings in which mitigation has been studied, speech and language intervention rarely contains the delivery of bad news, or criticism. Instead, communicative problems are to be worked on constructively in order to be improved over time. Since exercises during intervention bring the patient's problems to the surface, the SLP needs to manage this potentially delicate situation somehow. This is done by means of practices that we will argue are more of a defusing than of a mitigating character: within speech and language intervention, such practices do not only serve a mitigating purpose, e.g. when delivering bad news, but also the purpose of making the situation less delicate for the patient, during a difficult exercise related to the patient's specific speech and language problems. 
The article is structured as follows. In the literature review, some relevant issues on speech and language intervention and mitigation within clinical contexts are described. In the methods section, details about participants, data and analytical framework are described. The results section begins with a quantitative description of the defusing practices identified, followed by sequential analyses of representative examples to highlight their function. In the discussion, results are contextualised in relation to previous research. The article is concluded with suggestions regarding clinical implications.

\section{Literature review}

Speech and language intervention is mainly carried out in clinical settings of an institutional nature. A patient attends therapy because of a perceived deficit in communicative competence, and the SLP's expertise is used to provide the appropriate diagnosis and treatment. SimmonsMackie and Damico (1999: 313) referred to the 'inherent paradox' in speech and language therapy, as both SLP and patient assume their roles with a presupposition of the patient's deficit as the focus of attention. With this deficit-focused approach, speech and language intervention is likely to include a certain amount of face-threatening situations. As professionals in intervention try to bring along changes in a patient's behaviour, situations when someone is corrected or asked to perform something that he or she has problems with, may impose on the patient's self-image or face wants, which is colloquially referred to as losing face (Goffman 1959).

Speech and language intervention for children and adults have many features in common, but may also differ in some respects. Intervention for children with speech and language problems is mainly focussed on the areas that the child has particular difficulties with as revealed by speech and language tests. For treatment of speech sound disorders, including phonological problems, there are several direct intervention methods for which there is evidence of efficacy (Williams et al. 2010: 28), such as minimal pair intervention (Baker 2010), multiple oppositions intervention 
(Williams 2010) and complexity approaches (Baker and Williams, 2010). The intervention program 'Talking about Speech' (Gardner 2006) was shown to generate direct changes in adult therapy talk.

The main goal of speech and language intervention for people with aphasia is to improve their communicative ability (Basso and Caporali 2001). There are different intervention directions. A symptom-based direction is based on theories of cognitive neuropsychology (Basso 2010; Herbert et al. 2003). A more functional direction is based on pragmatic theories (Ahlsén 1995; Basso 2010). An important contribution to the increased focus on conversation in aphasia intervention is Kagan's $(1995,1998,1999)$ work on 'Supported Conversation for Adults with Aphasia' (SCA). SCA is a method, based on supportive dialogue models, that involves the training of people who surround the person with aphasia to support interaction in various ways in order to overcome the barriers for communication and participation imposed by the aphasia. Another conversation-focused approach has been applied by Lock, Wilkinson and Bryan (2001a), and Lock et al. (2001b) in 'Supporting Partners of People with Aphasia in Relationships and Conversation' (SPPARC). It has been demonstrated that individually tailored input based on Conversation Analytic (CA) principles can positively affect the interactional behaviour of a patient with aphasia (Beeke et al. 2014). These findings get further support in a review article of CA-informed intervention for aphasia (Wilkinson 2014). In a comparison of interactions between people with aphasia and their spouses, and people with aphasia and SLPs it was demonstrated that SLPs were more reluctant to help and to reduce face-threat in interaction than were spouses (Lindsey and Wilkinson, 1999).

The focus on linguistic abilities, which have been assessed as problematic by formal speech and language tests, is the main part of therapy for children with LI, as well as adults with aphasia, but the more functional approach in aphasia therapy is different from most intervention programs 
that are offered to children. The assumptions of prognosis are also different between children with LI and adults with aphasia, in that a full recovery is expected more often in the children. Another difference is that in young children, the SLPs are working with a still developing system, and intervention should support development in the right direction, whereas in adults with aphasia, intervention is rather supposed to support existing abilities and prevent them from deteriorating further. These similarities and differences between intervention for children with speech and language impairment and adults with aphasia make it relevant to compare these two types of intervention with regards to defusing strategies.

Mitigation, as defined by Fraser (1980), describes the rhetorical features that people use in order to avoid face-threatening situations in conversation (Brown \& Levinson, 1987). Mitigation in clinical interaction has previously mainly been described in terms of reducing the discomfort of giving and receiving bad news (Caffi 1999; Flores-Ferrán 2010; Peräkylä et al. 2008). Mitigating actions may, for example, result in motivating a patient to continue with treatment (Flores-Férran 2010). The concept of mitigation was described in a study of doctor-patient conversations by connecting pragmatics, rhetorical and psychological approaches (Caffi 1999). Caffi (1999) proposes that mitigations that reduce an addressee's obligations belong to the deontic modality (i.e. the linguistic modality that indicates how things ought to be according to e.g. speaker desire), and that mitigations that reduce the speaker's obligations belong to the epistemic modality (i.e. the linguistic modality that concerns the speaker's degree of confidence or knowledge).

Similar findings to those of Caffi (1999) were also made in Spanish psychotherapeutic discourse (Flores-Ferrán 2010). In addition to previous results, it was demonstrated that the mitigation devices used were determined by the therapist's intention to motivate the client to continue the therapy. Flores-Ferrán (2010) argues that there are also culture-specific interactional features relevant to mitigation. 
In a CA-study of interactions between neurologists and patients, mitigation was classified according to the amount of formulation effort that the neurologist puts into the conversation, and it was demonstrated that doctors employed most effort when they were discussing the aetiology of the patients' diagnosis (Monzoni et al. 2011). Mitigation may also result from either a cognitive stressor (corresponding to the epistemic modality), or from a social stressor (corresponding to the deontic modality), and mitigating devices vary depending on what contextual factors prompt them (Czerwionka 2010). In CA-studies, mitigating practices are primarily described according to their interactive aspects, and they may be labelled in various ways. The benefits of the CA-approach are that mitigations are analysed in terms of how they emerge sequentially, and what jobs they perform on a moment-to-moment basis. In a study of vagueness in everyday conversation, it was shown that vague expressions may serve as softening implicit criticism, and the authors argue that the success of a strategy depends on participants' degree of common ground (Jucker et al. 2002).

In sum, there may be a need for mitigation in speech and language intervention for both children with LI and adults with aphasia. The sequential focus of CA provides a useful means for investigating how mitigation emerges in speech and language intervention. The studies on mitigation referred to above do not cover the specific strategies used in speech and language intervention, where the practices seem to be serving the defusing purpose of saving the face of communicatively challenged others, by positioning them as competent interactional partners despite the fact that the interaction per se targets precisely a language or communication difficulty. Thus, the aim of the present paper is to describe the use and function of these kinds of defusing practices in speech and language intervention. For clarity, and for comparison, we will use the term defusing in the analysis. Furthermore, defusing practices in intervention with children with LI and adults with aphasia will be compared. 


\section{Methods and data}

\section{Participants}

Eight children with LI and six adults with aphasia as well as four SLPs specialized in intervention for children and five SLPs specialized in aphasia participated in the study (Tables 1 and 2).

[Insert Tables 1 and 2 about here]

\section{Data and analytical framework}

The material comprises video and audio recordings of eight intervention sessions with children with LI, and six intervention sessions with adults with aphasia, approximately 15 hours of audio and video recordings in total. The recordings captured routine therapy sessions. The material as a whole was transcribed in accordance with CA-conventions. Each line of original language (Swedish) is followed by a translation into English, marked by italics. The emic stance taken within CA (Sidnell 2010) influenced how the recordings of interaction from intervention and everyday talk involving the children with LI were analysed. The recordings were watched and listened to repeatedly and subsequently transcribed. Transcriptions were then discussed and revised several times by the first two authors. CA informed the present study in terms of it being driven by 'unmotivated' looking (Sacks 1984), and it was during viewing, listening to, and transcribing recordings, that defusing practices stood out as relevant for further scrutiny. However, as the phenomenon was to be put into a theoretical context, face theory (Brown and Levinson 1987) and the concept of mitigation as defined by Fraser (1980) also appeared relevant, particularly as previous work on mitigating practices had been conducted in that area, and CAanalyses revealed that participants appeared to be orienting towards aspects of face. 
The instances of defusing practices found in the data were further divided into categories according to their form and/or function as demonstrated in the interaction. It should be noted that the occasions where patients used defusing practices were very few, consisting primarily of an adult patient laughing at his own performance in a face-saving manner. Focus here is therefore devoted to SLPs' defusing practices. In previous work regarding people with aphasia, there are descriptions of adaptation practices (Heeschen and Schegloff 1999; Wilkinson et al. 2003), where it is argued that the use of telegraphic utterances or 'general meaning' forms are adaptations to the linguistic problems caused by the aphasia, thus serving as a resource in interaction. But such examples are quite different compared to the explicit ways of reducing unwelcome effects in clearly face threatening sequences, which is what is defined as mitigation in the present data. There were no instances of the previously described use of laughter or humorous noting in order to reduce the embarrassment of displays of incompetence made by people with aphasia (Wilkinson 2007).

\section{Results and Analysis}

The defusing practices identified in the data consisted of circumscriptions/figurative language, diminutive words, words like 'try' or 'test', placing the problem outside of the patient, including oneself in the intervention by the use of the collective pronoun we, diminishing the SLP's own competence, encouragement and understanding, and reference to well-known phenomena (e.g. this happens with age). Their frequency of occurrence is presented in Table 3.

[Insert Table 3 about here]

As regards the total number of defusing practices used by the SLPs, the proportion is significantly higher for intervention for children with LI compared to intervention for adults with aphasia $(\mathrm{p}<.05)$, and the sessions that comprised the most occurrences of defusing strategies 
concerned phonological intervention for children with LI (Figure 1). This indicates that some intervention activities are treated by SLPs as potentially more face-threatening than others, and perhaps also suggests that SLPs orient towards children as more vulnerable than adults in situations in which their language problems are targeted.

[Insert Figure 1 about here]

In what follows, sequential analyses of representative examples of the defusing practices observed in the data will be presented. Example 1, from intervention for a child with LI, illustrates the use of figurative language, as well as the use of a collective pronoun, in this case in combination with the defusing 'try' (prova). The child and the SLP are involved in a picture naming game which targets the sound /f/. An arrow in the left-hand margin of the excerpt and bold face mark particular points of interest.

\section{Example 1}

SLP=Speech and language pathologist, $C=C h i l d$

01 SLP: $\quad$ va va $\uparrow$ dä då

what was that then

02 C: en tot

a toot ((mispronunced))

$\rightarrow 03$ SLP: en fot (.) hörde du vad de börja med för ljud (0.3) de

$\rightarrow 04 \quad$ va ju den där raketen eller hur?

a foot (.) did you hear what it started with what sound (0.3) it was that rocket wasn't it

05 C: $\quad$ aaha $=$

06 SLP: =ha hur låter den då kommer du ihåg?

=ha what does that sound like then do you remember

07 C: fs ((knappt hörbart))

fs ((hardly audible)) 


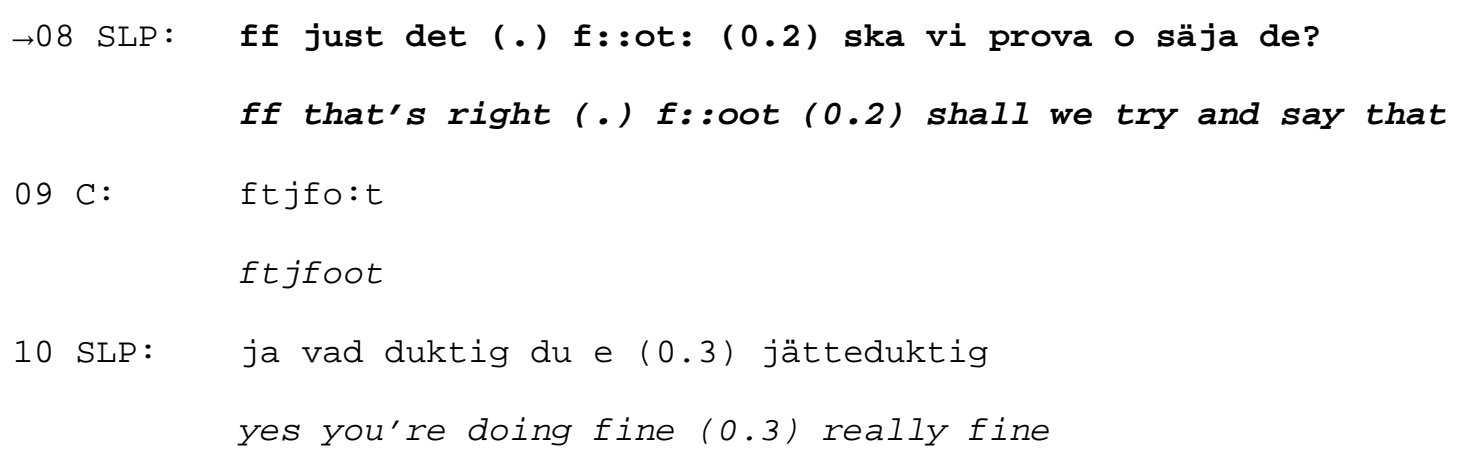

The sequence starts with a direct request for naming (01), which is responded to with a semantically correct answer from the child (02). However, the pronunciation is not correct. The child has here exposed exactly the problem to be worked on, and the SLP thne tries to make the child notice how the target sound should be pronounced. This is done by directing the child's attention towards the initial part of the word by means of a meta-linguistic question, and reminding the child of the figurative 'rocket' from the Nuffield dyspraxia method (Williams et al. 2010), referring to this as shared knowledge from a previous occasion ('it was that rocket wasn't it') (03-04). The child provides a confirmation (05), and the SLP continues by asking if the child remembers the sound of the rocket (06). In line 07 , the child tries to produce the requested sound very quietly, which is only partially correct. The SLP confirms the attempt and repeats the targeted sound with prolongation and asks the child to try again using the collective pronoun 'we' (08). This use of the pronoun is inclusive, and signals that the task is a mutual endeavour of the SLP and the child, which removes some of the responsibility for success from the child and defuses face-threat. A similar use of 'we' has been described as a diminishing and mitigating practice in child-directed speech (Greiser and Kuhl 1988; Foster 1990) and in elderspeak (Caporael 1981; Kemper 1994). This mitigating use of 'we' instead of 'you' is quite different from the use of 'we' instead of 'I', described in research on talk in the workplace, where the 'we' serves an act of the professional not taking the full responsibility for his/her utterance. Aronsson and Rundström (1988) also found frequent use of 'we' instead of ' $\mathrm{I}$ ' or 'you' in interactions between paediatricians and children, and described this as positive politeness functioning to increase 
familiarity in potentially threatening situations. The use of 'we' here appears to serve a similar purpose. The next try by the child (09) is positively assessed by the SLP (10).

In sum, the erroneous pronunciation by the child is oriented to as potentially face-threatening by the SLP, who prepares the child for a more direct request for production of the target sound (06) following the prompt by means of the figurative 'rocket' (04). The prompt probably also serves a defusing purpose, since it gives the activity a more playful and less face-threatening touch, which is also one of the pedagogical ideas of the Nuffield-program (Williams et al. 2010).

In example 2, a SLP and a child with LI are playing a memory game with pairs of pictures. There is no erroneous production, but the SLP uses the word 'try' when she asks the child to produce a certain word.

\section{Example 2}

SLP=Speech and language pathologist, $C=C h i l d$

09 SLP: $\quad$ va tror du de ä för nånting

what do you think that is

$10 \mathrm{C}: \quad$ ja sej ingen hatt

I seey no hat

11 SLP: de e faktiskt en s:äck

it's actually a sack

$12 \mathrm{C}:$ jaha

oh

$\rightarrow 13$ SLP: kan du prova o säja säck?

can you try to say sack

$14 \mathrm{C}: \quad$ scheck

scheck ((mispronunced))

15 SLP: ja va bra

yea that's good 
Initially, the SLP asks a direct question to the child (09). The child is focused on the game, and responds by saying that she does not see the second part of her pair of cards (10). The SLP explains what the picture depicts (11) with a prolongation of the target sound of the intervention /s/, which is minimally responded to by the child (12). The SLP then asks the child to try to say the intended word (13). The use of the word 'try' may be viewed as implying that the child's attempt need not be spotless, and it perhaps also signals that the SLP anticipates a potential difficulty, which might be face-threatening, as a deviant production will highlight the child's specific problem, which might also require further 'tries'. However, the child produces the word asked for (14), pronounced with a slight lateralization of the targeted /s/ (14). This answer is confirmed and accepted by the SLP (15). It may be noticed that this good try is only affirmed by the SLP, but the target word is not repeated again by the SLP, so the child is not provided with repeated phonetic information, something which has been suggested by Gardner (2006) as beneficial for the child's subsequent success.

Example 3 illustrates how the SLP places the problem outside of the child with LI by addressing a body part, the tongue, when instructing the child how to produce a certain sound. This sequence comes from a part of the session where the child and the SLP are working on the production of the target sound, $/ \mathrm{k} /$, in isolation.

\section{Example 3}

SLP=Speech and language pathologist, $C=$ Child

$\rightarrow 280$ SLP: där försök hålla bort tungan där nere $i$ underkäken $k$ there try to keep the tongue away down there in your lower jaw $k$

$281 \mathrm{C}: \mathrm{t}$

$\rightarrow 282$ SLP: och där åkte den upp lite $k$

and there it went up a little $k$

$283 \mathrm{C}: \mathrm{t}:$

284 SLP: en gång till mm ner med tungan 


\section{once more $\mathrm{mm}$ down with the tongue}

$285 \mathrm{C}: \quad \mathrm{k}$

286 SLP: där ah (2.5) och eh: kan du öppna munnen lite så ja ser

In example 3, the SLP instructs the child where to put his tongue (280), and the child responds with an erroneous production (281). This is commented on by the SLP solely by reference to what the tongue does (282), but the child's second try is also erroneous (283). The SLP then requests another try, adding a new instruction about keeping the tongue down (284), which results in a correct production from the child (285). In line 286, the SLP confirms the production, but wants to check the specific placement of the tongue. The child continues with producing the sound again, this time in the dentalized version (288), which might then be perceived as failing after having managed to produce the correct sound once. Whether or not this failure is experienced as potentially face-threatening by the child, it appears to be treated as such by the SLP, who again refers to the behaviour of the tongue in a laughing voice, rather than to the child being responsible for the error (289). In accordance with Gardner (2006), the SLP also again provides a production of the correct version of the target sound $/ \mathrm{k} /$, which is successfully produced by the child in the next turn (290).

Example 3 illustrates several corrective contributions from the SLP with potential facethreatening features. Not only is the child's initial inability to produce the correct sound in focus, as each incorrect production requires a corrective action by the SLP, but the activity at hand is 
also fairly intimate, with a close-up inspection of the movement of the tongue within the child's mouth - something that might be experienced as potentially imposing. The SLP appears to deal with these issues by placing the focus of correction on the tongue as partly doing problematic things independent of the child. This way of 'putting the blame' for an erroneous production on a body part as in line 289, where the tongue is ascribed an agentive role when it is claimed to be dodging away, is similar to the ways in which unsatisfactory performances are mitigated by physiotherapists in interaction with children with cerebral palsy (Holck et al. 2009). Similarly to examples 1 and 2, the SLP also employs the verb 'try' (280), which indicates that an entirely correct answer is not a necessity. Also, the diminutive 'a little' $(282,286)$ may serve a defusing purpose here. The child is co-operative in the activity, and eventually produces the target sound (290).

Example 4 is another case of how the SLP places the problem outside of the child, this time by means of referring to an artefact, a toy frog. Here, the SLP and the child are engaged in producing the target sound / $\mathrm{t} /$ in a sound sequence that becomes the word 'ta' in Swedish, which means 'take' in English.

\section{Example 4}

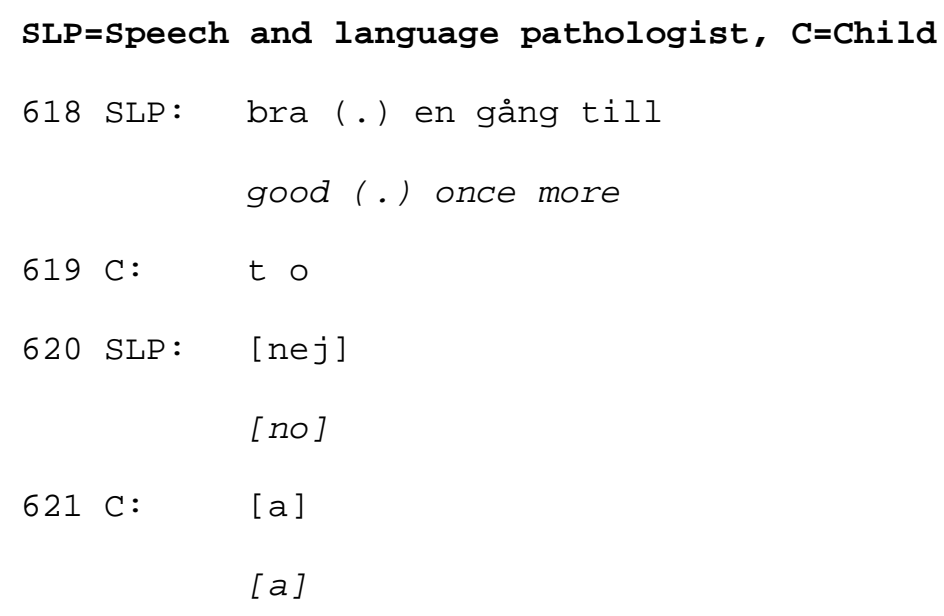




\section{a you know what the frog must do it again because he was a bit [uncertain] about the sound}

$624 \mathrm{C}:$

[t 0$]$ a

625 SLP: bra (.) men du vi tar en gång till [t a]

good (.) but you we take it one more time [t a]

$626 \mathrm{C}:$

$\left[\begin{array}{ll}\mathrm{t} & \mathrm{a}\end{array}\right]$

$\rightarrow 627$ SLP: bra du vet du va det lät som grodan gjorde (.) det

$\rightarrow 628$ lät som han sa såhär (.) t o a (.) ska vi prova å se om

$\rightarrow 629 \quad$ han kan det

good you know what it sounded like the frog did (.) it sounded as if he said like this (.) $t o$ a (.) shall we try and se if he can do that

$630 \mathrm{C}: \mathrm{t}[\mathrm{a}]$

$t[a]$

Example 4 starts with a request for production by the SLP (618), which is responded to by a slightly deviant try (619), assessed as erroneous, in overlap with a minimal response from the child $(620,621)$. Interestingly, it is the vowel that is incorrectly produced and not the target $/ \mathrm{t} /$. To initiate an explicit other correction (Schegloff et al. 1977) in the way that the SLP does, may be viewed as a face-threating action, in comparison to other means by which self-repair may be facilitated. This is, however, amended as the SLP withdraws focus from the child, over to the frog, as the frog is told to have another go, since he was a bit unsure about the sound (622-623). The child produces a satisfying, but not entirely correct contribution (624), which is positively assessed by the SLP (625), i.e. 'a good try' (Gardner 2006). However, the SLP requests another try from the child (625), and models the target structure, which is successfully repeated by the child (626). This response gets a positive evaluation, but it is also pointed out that the frog was slightly wrong (627-628). This account is followed by a request for yet another try, and again, the 
SLP uses both the word 'try', and the inclusive pronoun 'we' (628-629). The child responds by producing the target structure correctly (630).

One of the goals in this intervention approach, i.e. the Nuffield dyspraxia method (Williams et al. 2010), is to get the sequencing of target consonants and vowels right, and it is thus a concern of the SLP that even if the target dental stop is correct, the following vowel should also be produced correctly. In example 4, the SLP has brought a toy frog into the intervention in order to reduce the face-threat towards the child in the intervention. The toy frog seems to take on the responsibility of the production, although it has not been established that it was required to produce a specific sound. Example 4 bears resemblance with example 3, since someone or something else than the child is held responsible for pronunciation errors. This may also explain why the SLP makes an unmitigated correction (619), as it is the frog and not the child who is corrected. A similar practice has previously been described in the use of the different 'Misters' in Metaphon (Dean and Howell 1986; Hulterstam and Nettelbladt 2002). The 'Misters' in Metaphon serve the defusing purpose of placing the productive effort on them rather than on the child, as well as serving as reminders of articulation places and manners. Repeated solicitation, and several erroneous attempts from the child, may be perceived as face-threatening. The use of a frog that can take a part of the burden of errors might reduce some of the pressure on the child, and make the child try several times, and defuse the stress of repeated correction. This way of using other voices in child language intervention is perhaps a more conscious technique than other defusing practices observed in the data. Nevertheless, their main purpose seems to be to reduce potential face-threat.

The first set of examples have dealt with children with LI. Below, data of defusing practices in interaction involving adults with aphasia are provided. Example 5 comes from an intervention session for an adult with aphasia, at a point where the task for the person with aphasia is to 
describe his family. It illustrates how the SLP uses encouragement and understanding in order to reduce the stress of the patient in a situation in which his rather severe word mobilisation problems become evident.

\section{Example 5}

SLP=Speech and language pathologist, A=Adult with aphasia

748 A: fy $f[a n]$

bloody [hell]

$\rightarrow 749$ SLP: $\quad$ [mm] det tar tid men det kommer fr[am nåt ]

[mm] it takes time but it goes for[ward]

750 A :

[de va väl]inte så ph.

[it was not] so ph.

$\rightarrow 751$ SLP: a: nä men ja förstår om du blir (0.3) galen ibland

a: no but I understand if you get (0.3) mad sometimes

752 A: joho \$du hh fy fan\$

yea \$you hh bloody hell\$

753 SLP: så

so

754 A: usch

usch ((Swedish expression of disgust))

In example 5, the defusing practice used by the SLP (749) is triggered by a negative exclamation from the patient (748). The SLP asserts that rehabilitation takes time, providing a realistic picture to the patient. At the same, an encouraging account of the fact that the patient is progressing is given (749). This explicit encouragement may be viewed as defusing as, apart from pepping the patient, it serves the purpose of reducing face-threat related to the patient's displayed production problems. The patient responds to this comment by diminishing his own performance (750), the severity of which is minimised by the SLP, although not neglecting the problems of the patient (751). This means of explicitly displaying understanding may be viewed as an emphatic move by 
the SLP to soothe the patient's distress (cf. Plejert et al. 2014). Nonetheless, the problems and frustration are upgraded by the patient $(752,754)$. In this excerpt, the encouraging and comforting comments from the SLP regarding the patient's performance are probably related to the fact that the patient's use of swearing here functions as a meta-comment of his feelings. It may also be the case that comfort, understanding and encouragement are specifically needed in order to encourage frustrated patients to pursue the intervention also at points where their communicative inabilities become painfully evident, and potentially face-threatening.

The last two examples illustrate how SLPs diminish their own competence, which serves a defusing purpose. Both examples come from intervention with adults with aphasia. In example 6, the SLP and the patient are talking about an activity that the patient attended. In example 7, the SLP and the patient are talking about travelling, and the SLP is using an atlas to help the patient point out where he has been.

\section{Example 6}

$S L P=$ Speech and language pathologist, $A=$ Adult with aphasia

$151 \mathrm{~A}$ : här borta hos här bo-

over here with here live-

152 SLP: menar du att du varit med Sofia: å Camilla nånst[ans]

do you mean that you've been with Sofia and Camilla some[where]

153 A:

[nä]e här

154

borta (.) här borta=

[no]over

here (.) over here=

$\rightarrow 155$ SLP: =ja: : nu vet ja ju vad du menar va trög jag ä (.) menar

$\rightarrow 156 \quad$ du boken?

=yea: : now I know what you mean how stupid I am (.) do you

mean the book?

$157 \mathrm{~A}: \quad \mathrm{ja}$ 


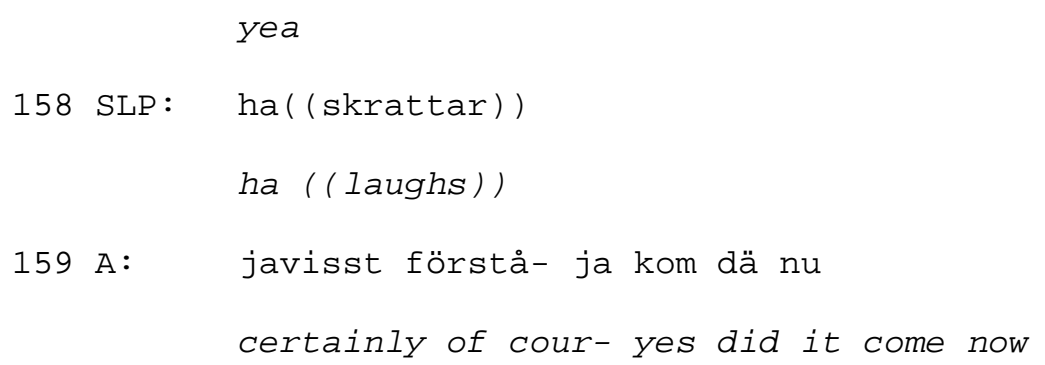

Example 6 begins with the patient saying something about a location somewhere (151). This is responded to by the SLP, who provides a candidate understanding of what she perceives to be a likely event to have occurred, based on knowledge that she shares with the patient (152). The SLP's candidate contribution is rejected by the patient and he restarts, recycling his prior spatial description ('over here') (154). This time the SLP understands that he refers to a book that he has left at the clinic, and she takes the full responsibility for the problem of understanding by diminishing her own competence when she implies that she was stupid not to understand this in the first place (155). In addition, this is accompanied by laughter, which may defuse the demonstration of her understanding difficulties (158). The SLP's understanding is confirmed by the patient $(157,159)$.

\section{Example 7}

SLP=Speech and language pathologist, $A=$ Adult with aphasia

245 A: =nånstans ((slår hanflatan $i$ bordet)) man flög ut ${ }^{\circ} u^{\circ}$

246 å så hoppa han ffly: ${ }^{\circ}$ garen så flygde man me ${ }^{\circ}$ =somehwere ((slaps palm on the table)) you flew out ${ }^{\circ}$ now $^{\circ}$ and then he jumped ffly:: ${ }^{\circ}$ er and you flew ((mispronounced)) with ${ }^{\circ}$

247 SLP: jaha nåt litet ställe?

oh some small place?

248 A: nä de va no v: va hetere man åker uppe fram: fan va de

249 heter (.) bababah

no it was no wh: what's its name you go up forward: damn what's its name (.) bababah 


\section{$\rightarrow 250$ SLP: du vet ju hur bra ja e geografi \\ you know how good I am at geography}

251 A: ja vist va fan $[\mathrm{du}]$

yea what the hell [you]

252 SLP:

$[(($ skrattar $))]$

[((laughs) $)]$

The patient is turning pages in the atlas and gets frustrated when he does not find a place that he has visited (245-246). The SLP poses a question to assist in the search (247), but the patient does not manage to come up with the name. Instead he displays his search by means of the formulaic 'what's its name' followed by some further description of the place and then the formula once more (248-249). This kind of formulaic expression may serve as a self-prompt, but here the SLP orients to it as a request for help and provides an ironic comment on her competence regarding geography (250), which is recognised by the patient (251).

The ways in which the SLPs diminish their own competence are fairly similar in examples 6 and 7. They illustrate how a face-threatening situation, where the patients' language problems lead to difficulties in achieving mutual understanding, may be defused by the SLP taking responsibility for the problem. It might be argued that the face of the SLP is threatened by means of this strategy, and indeed it is. However, the clinical setting with one professional and one patient is, in many respects, asymmetrical in favour of the SLP in terms of dominance and knowledge, which might to some extent explain the use of this strategy.

\section{Discussion}

In previous research, including studies on clinical interaction, mitigating practices have been described mainly as devices used in order to reduce unwelcome effects of an utterance (Fraser, 1980), or reduce the discomfort of bad news (Caffi 1999; Flores-Ferrán, 2010). However, in the 
present study, we have described a special variety of mitigation, that we call defusing practices, which have a rather different function. Defusing practices are used in order to save the face of communicatively challenged others, by distancing them from their incompetent selves in moments of exposed difficulties during intervention. This can be done by using figurative speech (example 1), using the word 'try' (example 2), the diminutive 'little' (example 3), making a body part an agent in the intervention (example 3), or bringing in an object, like a toy (example 4), encouraging comments (example 5), or reducing the therapist's own competence (examples 6 and 7).

The present study also revealed interesting differences regarding the use of defusing strategies between intervention for children with LI, and intervention for adults with aphasia. The differences found may be due to factors inherent in the activities that participants were involved in, but they may also be related to differences in interactional features of adult-adult interaction vs. adult-child interaction. However, regardless of explanations related to activities or age differences, the identification of these differences may provide useful insights for SLPs, as an informed use of defusing practices may improve compliance, stamina and motivation in speech and language intervention. As explained by Simmons-Mackie and Damico (1999: 313), the inherent paradox of speech and language therapy means that both the patient and the therapist assume their roles with a presupposition of the patient's deficit as focus of attention, and this in turn results in the fact that a number of potentially face-threatening sequences that call for some sort of defusing practice will occur during intervention sessions. The fact that language is the problem of the patient, and thereby the focus of intervention, differentiates speech and language intervention from clinical interaction that deals with other kinds of patient concerns/diseases, where mitigating strategies have previously been described. 
The need for defusing strategies also seems different between different types of intervention for children with LI. Direct, individual phonological intervention was the most frequently used type for the participating children in the present study, and it mainly focused on the production of specific sounds, both in isolation, and in words. The techniques used comprised both imitation and spontaneous production, and since the target sounds are exactly the sounds that the child has difficulties with, these exercises run the risk of being face-threatening, as well as unrewarding to the children. Thus, it is reasonable to assume that the defusing practices used in this type of intervention are a routinized practice in the SLPs' execution of the intervention. Intervention concerning grammar is not very frequent in the present data, but grammatical intervention is often made by the use of corrective recasts or clarification requests (Saxton 2005; Saxton et al. 2005) - techniques that are possibly less face-threatening than phonological intervention.

In intervention for adults with aphasia, the main goal is to improve the patient's communicative ability (Basso and Caporali 2001), and specific linguistic features are not the focus of intervention to the same extent as in intervention for children with LI. The intervention studied in the present data, although focussing on language symptoms, mainly did consist of conversation between the therapist and the patient on different topics. This makes the goals of intervention, and thereby the targeted features, less salient than e.g. in phonological intervention for children, hence the need for defusing strategies may be less pronounced. However, the language problems of the patient are salient and there are several occasions where the patient demonstrates frustration over the situation, which results in defusing practices from the therapist in terms of emphatic moves, encouragement, and also the diminishing of the SLP's own skills. Within language intervention, there is also a presupposition that adults with aphasia who attend intervention are in many cases expected to be aware of their problems, and thus motivated to participate, at least to some extent. This is in contrast to what is usually expected from children, and something that may also explain the higher frequency of defusing strategies from SLPs in interaction involving children. 


\section{Clinical Implications}

If SLPs become aware of the use and functions of various defusing practices, including how they are adapted to an activity and a clinical group, they may make conscious use of defusing devices in order to reduce and handle face-threatening situations in intervention. Such awareness-raising may be achieved in retrospective sessions with SLPs, but retrospective sessions may also be used in order to get SLPs comments on their use of defusing practices (cf. Samuelsson and Plejert 2014, on the use of retrospection in language intervention), and if their use of those practices is conscious or not. Our results may also be used in SLP education, e.g. by pointing these devices out to students in clinical practice or even teaching students to consciously use certain defusing devices.

\section{Transcription conventions}

\begin{tabular}{|c|c|}
\hline yes & stress \\
\hline really $\uparrow$ & rise \\
\hline ye:::a & prolonged sounds \\
\hline- & cut off word \\
\hline$=$ & speech immediately latched on to the previous utterance \\
\hline${ }^{\circ} \mathrm{mhm}^{\circ}$ & word or utterance pronounced quietly or soft \\
\hline.$h \mathrm{~h}$ & inbreath \\
\hline$\$$ & laughing voice \\
\hline$()$. & micro-pause (less than $0.2 \mathrm{sec}$.) \\
\hline$(0.4)$ & pause \\
\hline [ & overlapping speech \\
\hline
\end{tabular}

\section{References}

Ahlsén, E. (1995) Pragmatics in Aphasia - An Activity Based Approach. Gothenburg Papers in Theoretical Linguistics 77.

Aronsson, K. and Rundström, B. (1988) Child discourse and parental control in peadiatric consultation. Text 8 (3):159-190.

Baker, E. (2010) Minimal pair intervention. In A. L. Williams, S. McLeod and R. J. McCauley (Eds.) Interventions for Speech Sound Disorders in Children, 41-73. Baltimore: Paul H Brookes Publishing Co.

Baker, E. and Williams, A. L. (2010) Complexity approaches to intervention. A.L. Williams, S. McLeod and R. J. McCauley (Eds.) Interventions for Speech Sound Disorders in Children, 95-117. Baltimore: Paul H Brookes Publishing Co. 
Basso, A. (2010) Natural conversation: A treatment of severe aphasia. Aphasiology 24: 466-479.

Basso, A. and Caporali, A. (2001) Aphasia therapy or the importance of being earnest. Aphasiology 15: 307-332.

Beeke, S., Johnson, F., Beckley, F., Heilemann, C., Edwards, S., Maxim, J. and Best, W. (2014) Enabling better conversations between a man with aphasia and his conversation partner: incorporating writing into turn taking. Research on Language and Social Interaction 47: 292-305.

Blum-Kulka, S. (1990). You don't touch lettuce with your fingers: Parental politeness in family discourse. Journal of Pragmatics 14: 259-288.

Brown, P. and Levinson, S. C. (1987) Politeness - Some Universals in Language Use. New York: Cambridge University Press.

Brumark, A. (2006) Regulatory talk and politeness at the family dinner table. Pragmatics 16 (2/3): $171-211$.

Caffi, C. (1999) On mitigation. Journal of Pragmatics 31: 881-909.

Caporael, L. R. (1981) The paralanguage of caregiving: Baby talk to the institutionalized aged. Journal of Personality and Social Psychology 40 (5): 876-884.

Czerwionka, L. A. (2010). Mitigation in Spanish Discourse: Social and Cognitive Motivations, Linguistic Analyses, and Effects on Interaction and Interlocutors. Unpublished Doctoral Thesis, University of Texas, Austin.

Dean, E. and Howell, J. (1986) Developing linguistic awareness: A theoretically based approach to phonological disorders. British Journal of Disorders of Communication 21: 223-238.

Flores-Ferrán, N. (2010) An examination of mitigation strategies used in Spanish psychotherapeutic discourse. Journal of Pragmatics 42: 1964-1981.

Foster, S., H. (1990) The Communicative Competence of Young Children. New York: Longman Inc.

Fraser, B. (1980) Conversational Mitigation. Journal of Pragmatics 4: 341-350.

Gardner H (2006) Training others in the art of therapy for speech sound disorders: an interactional approach. Child Language Teaching and Therapy 22 (1): 27-46.

Goffman, E. (1959) The Presentation of Self in Everyday Life. Harmondsworth: Penguin Books.

Grieser, D. L. and Kuhl, P. K. (1988) Maternal speech to infants in a tonal language: Support for universal prosodic features in motherese. Developmental Psychology 24 (1): 14-20.

Heeschen, C. \& Schegloff, E.A. (1999) Agrammatism, adaptation theory, conversation analysis: on the role of so-called telegraphic style in talk-in-interaction. Aphasiology 13 (4-5): 265-405.

Herbert, R., Best, W., Hickin, J., Howard, D. and Osborne, F. (2003) Combining lexical and interactional approaches to therapy for word finding deficits in aphasia. Aphasiology 17: 1163-1168.

Holck, P., Dahlgren Sandberg, A. and Nettelbladt, U. (2009) Interaction during intervention: Conversations between professionals and children with cerebral palsy. Communication \& Medicine 6: 49-60.

Hulterstam, I. \& Nettelbladt, U. (2002) Clinician elicitation strategies and child participation. Comparing two methods of phonological intervention. Logopedics Phoniatrics Vocology 27(4): 155-168.

Jucker, A. H., Smith, S. W. and Lüdge, T. (2003) Journal of Pragmatics 35: 1737-1769.

Kagan, A. (1995). Revealing the competence of aphasic adults through conversation: A challenge to health professionals. Topics in Stroke Rehabilitation 2: 15-28.

Kagan, A. (1998) Supported conversation for adults with aphasia: methods and resources for training conversation partners. Aphasiology 12 (9): 816-830.

Kagan, A. (1999) Supported Conversation for Adults with Aphasia: Methods and Evaluation. Unpublished Doctoral Thesis, University of Toronto.

Kemper, S. (1994) Elderspeak: Speech accommodations to older adults. Aging and Cognition 1(1): $17-28$. 
Lindsey, J. and Wilkinson, R. (1999) Repair sequences in aphasiac talk: A comparison of aphasicspeech and language therapist and aphasic-spouse conversations. Aphasiology 13 (4-5): 305325.

Lock, S., Wilkinson, R. and Bryan, K. (2001a) SPPARC: Supporting Partners of People with Aphasia in Relationships and Conversations. Bicester: Winslow Press.

Lock, S., Wilkinson, R., Bryan, K., Maxim, J., Edmundson, A., Bruce, C. and Moir, D. (2001b) Supporting partners of people with aphasia in relationships and conversation (SPPARC). International Journal of Communication Disorders 36 (Suppl): 25-30.

Monzoni, C. M., Duncan, R., Grünewald, R. and Reuber, M. (2011) How do neurologists discuss functional symptoms with their patients: A conversation analytic study. Joumal of Psychosomatic Research 71: 377-383.

Peräkylä, A., Antaki, C., Vehviläinen, S. and Leudar, I (Eds.) (2008) Conversation Analysis and Psychotherapy. Cambridge: Cambridge University Press.

Plejert, C., Jansson, G. and Yazdanpanah, M. (2014) Response practices in multilingual interaction with an older Persian woman in a Swedish residential home. Journal of CrossCultural Gerontology 29: 1-23.

Sacks, H. (1984) Notes on methodology. In J. M. Atkinson and J. Heritage (Eds.) Structures of Social Action: Studies in Conversation Analysis, 21-27. Cambridge: Cambridge University Press.

Sacks, H. (1987) On the preferences for agreement and contiguity in sequences in conversation. In G. Button and J. R. E. Lee (Eds.) Talk and Social Organisation, 54-69. Clevedon, England: Multilingual matters.

Schegloff, E. A, Jefferson, G. and Sacks, H. (1977) The preference for self-correction in the organization of repair in conversation. Language 53 (1-2): 361-82.

Samuelsson, C. and Plejert, C. (2014) On the use of conversation analysis and retrospection in intervention for children with language impairment. Accepted for publication in Child Language Teaching and Therapy.

Saxton, M. (2005) 'Recast' in a new light: insights for practice from typical language studies. Child Language Teaching and Therapy 21: 23-38.

Saxton, M., Houston-Price, C. and Dawson, N. (2005) The Prompt hypothesis: Clarification requests as corrective input for grammatical errors, Applied Psycholinguistics 26 (3): 393-414.

Sidnell, J. (2010) Conversation Analysis: An Introduction. Chichester: Wiley-Blackwell.

Simmons-Mackie, N. and Damico, J. S. (1999) Social role negotiation in aphasia therapy: Competence, incompetence and conflict. In D. Kovarsky, J. Duchan and M. Maxwell (Eds.) Constructing (In)Competence: Disabling Evaluations in Clinical and Social Interaction, 313-342. Mahwah: Lawrence Erblaum Associates Inc.

Wilkinson, R. (2007) Managing linguistic incompetence as a delicate issue in aphasic talk-ininteraction: On the use of laughter in prolonged repair sequences. Journal of Pragmatics 39 (3): 542-569.

Wilkinson, R. (2014) Intervening with conversation analysis in speech and language therapy: improving aphasic conversation. Research on Language and Social Interaction 47: 219-238.

Wilkinson, R., Beeke, S. and Maxim, J. (2003) Adapting to conversation. On the use of linguistic resources by speakers with fluent aphasia in the construction of turns at talk. In C. Goodwin [incomplete]

Williams, A. L. (2010). Multiple oppositions intervention. In A. L. Williams, S. McLeod and R. J. McCauley (Eds.) Interventions for Speech Sound Disorders in Children, 73-94. Baltimore: Paul H Brookes Publishing Co.

Williams, A. L., McLeod, S. and McCauley, R. J. (2010) Interventions for Speech Sound Disorders in Children. Baltimore: Brookes Paul H Brookes Publishing Co. [Chapter 7: The Nuffield Centre Dyspraxia Programme, by Pam Williams and Hilary Stephens. - See more at: http://www.ndp3.org/dyspraxia-apraxia-reading-list.html\#sthash.7m7NkRt9.dpuf] 


\section{Tables}

Table 1. Participants, age, and type of language ipairment in the participating children.

\begin{tabular}{lll}
\hline Participant & Age & $\begin{array}{l}\text { Language } \\
\text { Impairment }\end{array}$ \\
1 & $5: 7$ & PI \\
2 & $5: 3$ & PI and GI \\
3 & $5: 4$ & PI \\
\hline 3 & $5: 7$ & PI \\
\hline 5 & $5: 1$ & PI and GI \\
\hline 6 & $5: 4$ & PI \\
7 & $5: 11$ & PI \\
8 & $4: 10$ & General \\
\hline PI=phonolgical impairment, GI=grammatical impairment
\end{tabular}

Table 2. Participants, age, and type of aphasia (from medical records) in the participating adults.

\begin{tabular}{lll}
\hline Participant & Ages & Aphasia \\
1 & 60 years & Severe global aphasia \\
2 & 80 years & Moderate afferent motor aphasia \\
3 & 60 years & Moderate Wernicke’s aphasia \\
4 & 60 years & Severe Broca's aphasia \\
5 & 70 years & Moderate afferent motor aphasia \\
6 & 60 years & Severe global aphasia \\
\hline
\end{tabular}


Table 3. Occurrence of defusion strategies in intervention with adults and children respectively.

\begin{tabular}{|c|c|c|}
\hline Defusing strategy & Aphasia intervention & Child language intervention \\
\hline $\begin{array}{l}\text { circumscriptions/ figurative } \\
\text { language }\end{array}$ & & $\mathrm{X}$ \\
\hline diminutive words & $\mathrm{X}$ & $\mathrm{X}$ \\
\hline words like "try" or "test" & & $\mathrm{X}$ \\
\hline $\begin{array}{l}\text { placing the problem outside of } \\
\text { the patient }\end{array}$ & & $\mathrm{x}$ \\
\hline collective pronouns & $\mathrm{X}$ & $\mathrm{X}$ \\
\hline $\begin{array}{l}\text { diminishing the SLP's own } \\
\text { competence }\end{array}$ & $\mathrm{X}$ & $\mathrm{X}$ \\
\hline encouragement & $\mathrm{X}$ & $\mathrm{X}$ \\
\hline $\begin{array}{l}\text { references to well-known } \\
\text { phenomena }\end{array}$ & $\mathrm{X}$ & \\
\hline
\end{tabular}

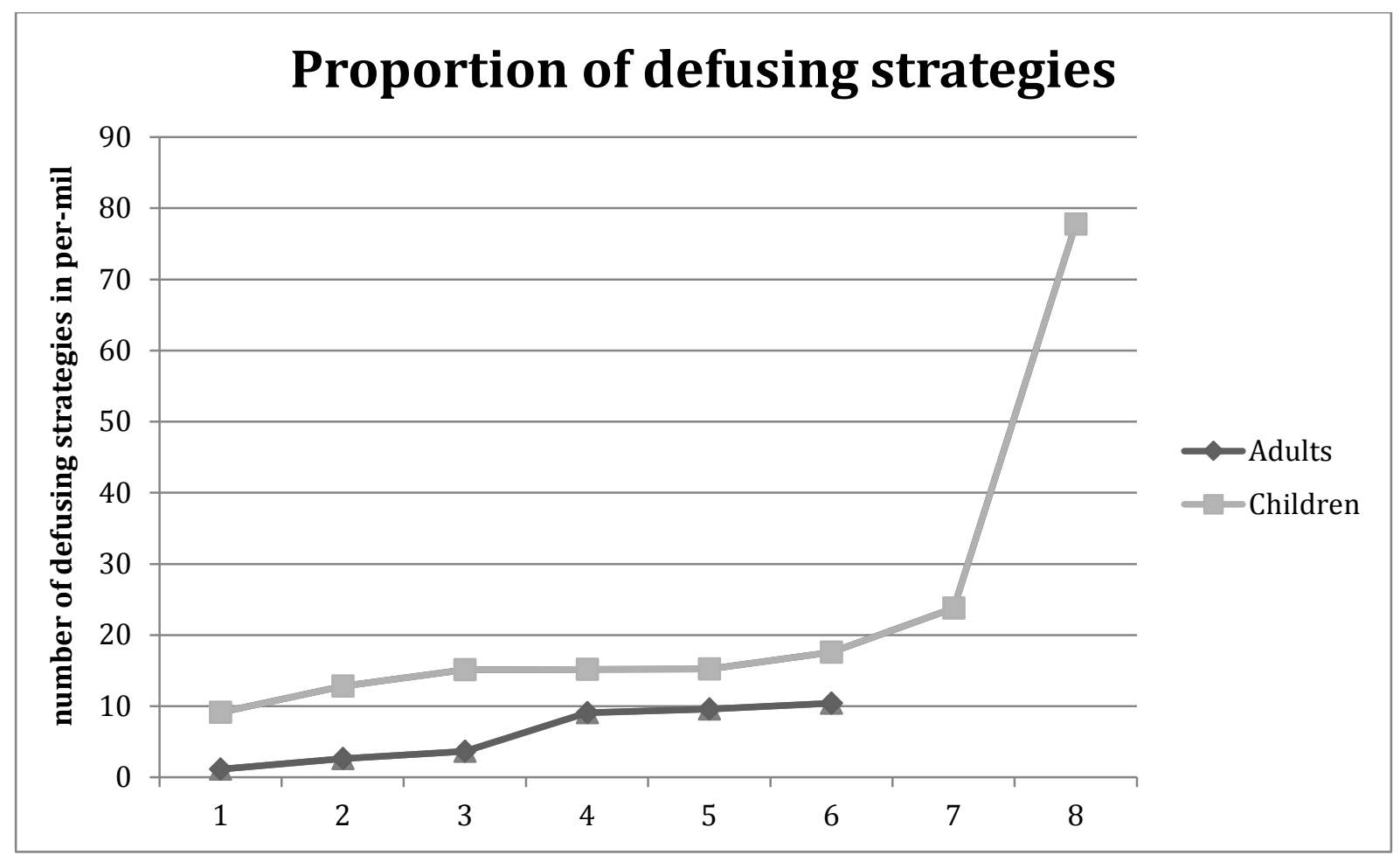

Figure 1. Proportion of defusing strategies used in intervention for adults with aphasia and for children with language impairment. 